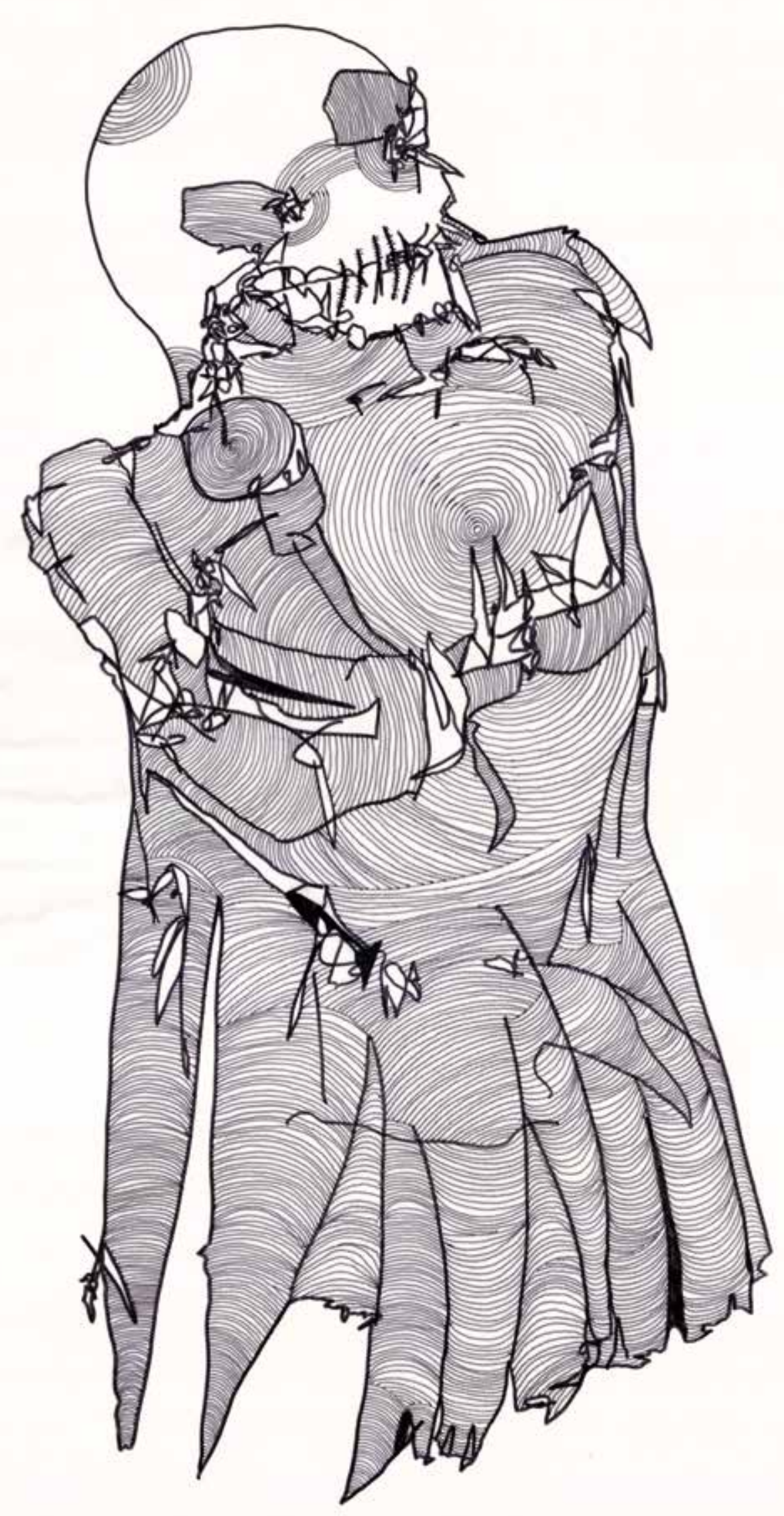


Pedagogía y Saberes No. 48

Universidad Pedagógica Nacional

Facultad de Educación. 2018, pp. 83-96

\section{Perfil de egreso y empleo en el contexto del avance tecnológico*}

Artículo de reflexión

Graduate and Job Profile in the Context of Technological Advancement

Perfil do egresso e emprego no contexto do avanço tecnológico

César Silva Montes **

Para citar este artículo:

Silva, C. (2018). Perfil de egreso y empleo en el contexto del avance tecnológico. Pedagogía y Saberes, 48, 83-96.

* El presente artículo es una reflexión derivada de mis trabajos sobre la aplicación del currículo basado en competencias en el bachillerato mexicano y la pertinencia de adecuar los contenidos escolares a la demanda de fuerza de trabajo en una economía regida por el libre mercado.

** Profesor de la Universidad Autónoma de Ciudad Juárez. Doctor en Ciencias Sociales de la Universidad Autónoma Metropolitana, unidad Xochimilco. Investigador del Grupo Cuerpo Académico \#54.

Correo electrónico: cesilva@uacj.mx

Código ORCID: orcid.org/0000-0003-0531-2911 


\title{
Resumen
}

El presente artículo es una reflexión derivada de la aplicación del currículo basado en competencias (CBC). El objetivo es comprender los efectos de este currículo en el perfil de egreso en el contexto de la creciente tecnologización y automatización de los nuevos empleos y las repercusiones en la contratación laboral en diferentes áreas de desempeño técnico y profesional. En el artículo se presenta una breve revisión histórica de la orientación que el currículo tuvo hacia la preparación para el trabajo en México. En seguida se propone una discusión sobre el CBC, su definición, sus ventajas y su atributo técnico en el perfil de egreso del siglo xxi. Después se plantea el debate sobre la economía del conocimiento y la promesa de mejoras en las condiciones de vida, señalando cómo las escuelas se esfuerzan por generar capital humano con las competencias tecnológicas e informáticas para un espacio laboral excluyente, precario, en el cual la automatización disminuye el empleo de personas. Finalmente, dos conclusiones son presentadas: primero que la adecuación de los contenidos y programas de estudio en competencias para ligarlo con el mercado laboral no garantiza un puesto de trabajo ni mejor remuneración; y segundo, que se forma un profesional despreocupado por la resolución de los problemas sociales.

\section{Palabras clave}

competencias; formación; sociedad del conocimiento; tecnología; exclusión

\begin{abstract}
This article is a reflection derived from the implementation of a curriculum based on competences ( $\mathrm{CBC}$ ). The aim is to understand the effects of such curriculum on the graduate profile in the context of the growing technologization and automation of new employments and the repercussions on the hiring process in different technical and professional areas. The paper makes a brief historical review of the curriculum's orientation towards preparing students for the job market in Mexico. Then, a discussion about the CBC is proposed, as well as its definition, its advantages, and its technical nature in the twenty-first century graduate profile. Next, the article proposes a debate about knowledge economy and the promise to improve life conditions, noting how schools strive to generate human capital with the technological and informatic competencies for an excluding and precarious space in which automation decreases people employment. Finally, two conclusions are presented: first, that adapting contents and study programs to competences in order to link it to the job market does not guarantee job positions or better salaries; and second, that it is creating professionals unconcerned with finding solutions to social problems.
\end{abstract}

\section{Keywords}

skills; training; knowledge society; technology; exclusion

\section{Resumo}

Este artigo é uma reflexão derivada da aplicação do currículo baseado em competências (CBC). 0 objetivo é entender os efeitos deste currículo no perfil do egresso no contexto da crescente tecnologização e automatização dos novos empregos e as repercussões na contratação laboral em diferentes áreas de desempenho técnico e profissional. No articulo apresenta-se uma breve revisão histórica da orientação que o currículo teve para a preparação do trabalho no México. Em seguida, propõe-se uma discussão sobre o CBC, sua definição, suas vantagens e seu atributo técnico no perfil do egresso do século XXI. Depois, considera-se o debate sobre a economia do conhecimento e a promessa de melhoras nas condições de vida, assinalando como as escolas se esforçam em gerar capital humano com as competências tecnológicas e informáticas para um espaço laboral excludente, precário, no qual a automatização diminui o emprego de pessoas. Finalmente, duas conclusões são apresentadas: a primeira é que a adequação de conteúdos e programas de estudo em competências para relacioná-lo com o mercado laboral não garante uma vaga de emprego nem melhor remuneração; e, segundo, que se forma um profissional despreocupado pela resolução de problemas sociais.

\section{Palavras-chave}

competências; formação; sociedade do conhecimento; tecnologia; exclusão 


\section{Introducción}

En la llamada economía del conocimiento el objetivo es adaptar el perfil de egreso de las escuelas a las demandas del mundo del trabajo, en especial en el bachillerato y la educación superior. El sustento principal de esta tendencia es la modificación en los procesos productivos generados por la revolución informática y el incesante cambio tecnológico. Con este referente, los gobiernos y las empresas intentan recuperar la inversión en el sistema educativo formando un capital humano renovado y global con los conocimientos, habilidades y actitudes para enfrentar los retos de la globalización del siglo XXI. Globalización con un sentido fundamentalmente económico que empuja a los países a buscar fortalecer su competitividad, en un mercado de productos cuya característica principal es la reducción del uso de la materia prima y el avance de la digitalización. A escala mundial y en México se implementaron reformas curriculares definidas, desde el empresariado, basadas en competencias para un planeta inestable (Silva, 2016a).

Según la Organización de las Naciones Unidas para la Educación, la Ciencia y la Cultura- Unesco (s. f.), los cambios económicos emanados de la globalización son una secuela de la revolución tecnológica que incluye la robótica, la biotecnología, la tecnología de la información y los nuevos materiales. En este marco se generaron efectos en la apertura comercial y la desregulación financiera, en la producción, en las creencias de la gente y la exclusión de la población de las ventajas de la tecnología. La Unesco observa la situación actual en modificación permanente y veloz que causa incertidumbre y obliga a todas las instituciones a revisar sus misiones y estructura para alcanzar sus fines, entre ellos la educación. El entorno es "Un mundo en cambio vertiginoso" (Unesco, s. f., p. 5), que pasó de las primeras computadoras personales y de oficina, a una cotidianidad de cajeros automáticos, teléfonos celulares, discos compactos y ordenadores en los hogares con capacidad para almacenar enormes cantidades de información.

En este contexto la educación formal se mueve entre distintos dilemas, como formar las capacidades de empleabilidad de las personas o la integración social, o servir de motor de la competitividad económica o para coadyuvar a la equidad social. Una posibilidad para la Unesco (s. f.) es desarrollar un currículo en competencias globales que se modifiquen de acuerdo con el desarrollo tecnológico y se enfoquen en la capacidad de las personas para buscar y procesar información. Se expresa como una alternativa a los currículos anteriores porque, semejante a una computadora en constante evolución, su vigencia en la escuela es reducida. De manera "natural", para la Unesco el empleo actual es fluctuante porque depende de las competencias requeridas por las nuevas tecnologías, entre otras, las aplicaciones informáticas como el control numérico y los procesos de calidad total que requieren renovar conocimientos y habilidades. Los criterios de selección del personal cambian y a la escuela se le exhorta a formar fuerza laboral polivalente y apta para el trabajo simbólico, de pensamiento sistémico y capacidad de trabajar en equipo. En síntesis, el perfil de egreso debe responder a un mundo donde el cambio se convierte en regla y la estabilidad en excepción.

Siguiendo la tendencia global, en México en el Programa Sectorial Educativo (PSE) 2007-2012 el diseño curricular se basó en la innovación de la globalización productiva y se estableció otorgar al estudiantado un certificado en competencias como apoyo para conseguir un empleo. Ello será posible con un currículo basado en competencias (СBC) que permite: "la pronta incorporación de los jóvenes al mercado de trabajo, formal o informal, muestra la relevancia de ofrecer opciones que combinen la formación integral con la preparación laboral" (Secretaría de Educación Pública [SEP], 2008, p. 21). Por su parte, el Consejo Nacional de Normalización y Certificación de Competencias (Conocer) promovió un "Sistema Nacional de Competencias de las Personas, que contribuya a la competitividad económica, al desarrollo educativo y al progreso social de todos los mexicanos". El fin es validar el capital humano que las personas han adquirido en su trabajo, y en lo educativo determina los estándares de competencia, entendida como "la aptitud de una persona para desempeñar un trabajo de manera exitosa" (Conocer, s. f.). En el caso del bachillerato, se postuló que:

\footnotetext{
Las competencias surgen en el ámbito internacional como respuesta a la necesidad de mejorar la calidad y la pertinencia de la formación de recursos humanos frente a la evolución de la tecnológica (sic), los nuevos sistemas de trabajo y para fomentar el aprendizaje permanente a lo largo de la vida, con el fin de mejorar la competitividad de las empresas, así como las condiciones de vida y de trabajo de la población en general. (Dirección General del Bachillerato [DGB], 2010, p. 8).
}

Valga la repetición de citas textuales para fundamentar la retórica común y la similitud de los conceptos en la era global educativa y de la también llamada sociedad de la información. En suma, se encuentran las constantes de la aplicación de las competencias en la escuela: dictar normas que certifiquen la 
preparación laboral de acuerdo con las necesidades del empresariado; enseñanza con énfasis en el aprender haciendo; la formación de capital humano con la mentalidad de competitividad; y la escuela se convierte en simple capacitación para el trabajo (Silva, 2016a). Muñoz (1993) denominó a esta estrategia teoría de la funcionalidad técnica de la educación; esta pretende con una planeación equilibrar el egreso y la demanda de fuerza de trabajo; si hay alguna disfuncionalidad entre formación y empleo es responsabilidad de las escuelas, pues no cumplen las demandas del mercado laboral. Se ignora que los mercados no son estables por la libre competencia y es imposible planificar para adecuar totalmente la oferta y la demanda de mano de obra.

Por otra parte, en el periodo de neoliberalismo económico, de acuerdo con Coriat (2005), se despoja al colectivo obrero de la seguridad social ganada en el periodo designado Estado de bienestar. El modelo de producción entonces se basó en el fordismo; en lo social, se consolidaron prestaciones como el servicio médico, la educación y la posibilidad de adquirir una vivienda. Para el pensamiento neoliberal, esto representó un alto costo para el Estado, con una excesiva burocracia y se consideró inviable (Uroz, 2010). En consecuencia, empezó la eliminación del derecho a la seguridad social para reorientar el gasto a la reducción de los déficits presupuestales y la deuda generados por los gobiernos. Durante la crisis económica de los años ochenta se recortó la inversión en servicios básicos para la población y se usó para impulsar el crecimiento económico (Midgley, 2001). En lo laboral se iniciaba el empleo precario (Castel, Kessler, Merklen y Murard, 2013; Sennet, 2000), entendido como la eliminación progresiva de contratos colectivos y de tiempo completo, prestaciones como el aguinaldo, las vacaciones y beneficios de la seguridad social, como el servicio médico. Además, la inestabilidad laboral aumentó la informalidad del empleo, la desregulación de las leyes laborales y la desaparición de los sindicatos para la defensa de sus derechos. El colectivo trabajador ahora labora bajo contratos flexibles, temporales o de subcontratación.

Con tales antecedentes, el propósito del artículo es reflexionar acerca de cómo las escuelas, en su afán por responder al avance tecnológico, diseñan un currículo con un perfil de egreso según las competencias genéricas para una sociedad del conocimiento excluyente y de empleo precario. Sin oponerse al uso de la tecnología, la robótica, la automatización y las computadoras ni al actual modelo de producción de manufactura esbelta, se cuestiona que su aplicación en la producción provoca desempleo y un currículo de formación para la competencia económica, más que para suscitar la integración social. Se entiende que el свC es producto de las políticas neoliberales y de contratación de la fuerza laboral, y su implementación en las escuelas no podrá resolver por sí misma el desfase escuela-trabajo o el mejoramiento de las condiciones de vida de la gente.

Para sustentar el análisis del ensayo, se expone un breve recuento histórico del currículo, en el cual se destaca su orientación hacia la preparación para el trabajo. Después de la discusión sobre el CBC, se presentan su definición, sus ventajas y su atributo técnico en el perfil de egreso del siglo XXI. Enseguida, se plantea el debate respecto a la economía del conocimiento y su efecto en la mejora de las condiciones de vida de la población. Más adelante, se muestra cómo las escuelas se esfuerzan por generar capital humano con las competencias tecnológicas e informáticas para un espacio laboral excluyente, precario y que con la automatización cada vez emplea a menos personas. Por último, en las conclusiones se delibera acerca de las competencias y la situación actual del perfil de egreso, su sentido en la formación de ciudadanos y se insinúa el futuro del empleo del nuevo profesional en la globalización educativa.

El punto de partida son los documentos de la Unesco (s. f.) donde se propone el diseño de un CBC global, y donde se esbozan matices sobre la sociedad del conocimiento y la mercantilización de la educación formal. El contexto es México y su respuesta a recomendaciones de organismo internacionales para adoptar el CBC e incluirse en la globalización económica. En esta senda, el currículo en su devenir es más que un plan de estudios: es una disputa por un proyecto de nación.

\section{Currículo y competencias}

El currículo es una construcción social e histórica que representa una idea de ser humano y sociedad, por esto es un espacio de conflicto. Su diseño es cultural y en ocasiones se limita a formar para el trabajo, pero también se plantea como una instancia de emancipación que revela la ideología subyacente porque reproduce las pautas de conducta del poder político y económico. En el currículo escolar se plasman los fines de la educación que se pretenden materializar mediante la descripción de los contenidos, métodos, objetivos, conocimientos y destrezas (Silva, 2016a). En la retórica de las reformas curriculares, como se evidencia en los documentos de la Unesco (s. f., 2005 y 2014) y del Gobierno mexicano, el fin es el bienestar en los países. En la globalización el currículo se adecúa a las tecnologías de la información, las demandas de competitividad del mercado y el perfil 
de egreso para el consumo. En este enfoque curricular se educaría con una didáctica industrial acorde con los objetivos de la resolución de problemas laborales y de trabajo en equipo, relegando la preocupación por las desigualdades sociales.

Para Lundgren (1997), el código curricular realista y racional proporcionó los elementos para la educación laboral. Apoyado en la ciencia para el usufructo de la naturaleza, en Estados Unidos fue la base para el desarrollo industrial y la conformación de mano de obra calificada. Por otro lado, delineó las ideologías del pragmatismo, el racionalismo y el aprender haciendo, enfocadas a manejar con eficiencia las máquinas en favor de la economía. En la década de 1920, según Salinas (2000) y Gimeno (2002), se desarrolló el currículo de la organización científica del trabajo para capacitar al colectivo obrero en las tareas pedidas por el empresariado. En consecuencia, los aspectos históricos, culturales, sociales y políticos se descartaron. A México esta propuesta llegó en los setenta con el impulso de la Organización de los Estados Americanos y la Organización Internacional del Trabajo (Barrón, 2013); allí el perfil de egreso es congruente con la teoría del capital humano, la meritocracia y el individualismo laboral. En el siglo XXI el currículo abona al modelo de obrero universal y polivalente a la producción toyotista o manufactura esbelta (Silva, 2016a).

En contraposición, Comboni y Juárez (2001) postulan un diseño curricular regional y decidido por sus miembros, que conservan su identidad, y en interacción con la cultura global. Por otra parte, en las escuelas es deseable la participación del profesorado en la definición curricular, los contenidos, los planes y programas de estudio, para trascender la separación de la planeación de especialistas externos a la escuela y el papel de ejecutores de maestros y maestras. Esta posibilidad propiciaría un debate sobre el perfil de egreso, si se orientara primordialmente al trabajo o a generar un pensamiento solidario y comprometido con la sociedad marginada. Permitiría aplicar los contenidos del currículo en interés del estudiantado, de sus diferencias y aspiraciones. Así el profesorado sería más más reflexivo e innovador, como se propone en el perfil de egreso de la era de la información: abstracción, pensamiento sistémico, pensar por sí mismo, analizar situaciones, resolver problemas y cooperar (Unesco, s. f.).

No obstante, en la escuela prevalece la corriente curricular funcionalista, que reproduce las formas sociales de pensar y actuar para disciplinar a la niñez y a la juventud (Comboni y Juárez, 2001). Aunque el discurso hegemónico invite a la construcción de un nuevo paradigma educativo y conectarlo con los intereses, necesidades, gustos y habilidades de cada estudiante (Unesco, 2014), permanecen las bases de la tecnología educativa y la enseñanza programada. Para estos enfoques, los contenidos de aprendizaje son algo legitimado que no requiere el cuestionamiento de docentes o estudiantes, en consecuencia, son neutrales y válidos para todos los espacios educativos.

En México, el CBC es el idóneo para tiempos de incertidumbre y de la economía del conocimiento porque "... la transformación de los procesos de producción en el ámbito internacional ha instaurado un nuevo referente para definir el contenido del trabajo: la competencia laboral" (SEP, 2001, p. 166). Su antecedente es la crisis económica de los setenta, que obligó a Japón a desconcentrar la producción e innovar la capacitación para el trabajo (Rojas, 2000). Además, se complementa con los cuatro pilares de la educación y la teoría del capital humano y se amolda al cambio tecnológico, porque las habilidades, conocimientos y actitudes adquiridos son transferibles mediante la normalización y certificación laboral (Silva, 2016b). Es la visión del reciclaje de la mano de obra, llamada con el eufemismo de educación a lo largo de la vida.

Respecto a la definición del término competencia, su significado es polisémico y se vuelve difuso, impreciso y pierde sentido. Para la Unesco (s. f.), es la integración de conocimientos, capacidades, representaciones y comportamientos movilizados para resolver problemas profesionales y obtener resultados de calidad. Implica conciencia sobre las consecuencias de sus acciones y supone capacidad para aprender, innovar y generar nuevos conocimientos. Trasciende las tareas rutinarias y específicas: una persona competente interviene en un mundo complejo desde los aspectos técnicos hasta los culturales, sociales, éticos, políticos y tecnológicos. La vasta definición no disminuye la ambigüedad. Báez (2006) sostiene que competencia puede significar cualquier cosa, y para encontrarle sentido requiere un apellido: básicas, específicas, académicas, profesionales, ocupacionales, sociales, laborales o emprendedoras. El diccionario del Reader's Digest (1985, p. 826) define la competencia a partir de su etimología latina competentía, como: "Disputa o contienda entre dos o más sujetos, rivalidad; también aptitud o con los conocimientos idóneos para realizar determinada actividad".

Las definiciones contemporáneas de competencia se relacionan con nociones industriales como competitividad, rentabilidad y eficiencia de la economía global (De Ketele, 2008). En consecuencia, los empleadores le exigieron a la escuela difundir las competencias transversales o genéricas para 
desarrollarse en la producción, como: ejercer la autonomía en el manejo de las máquinas; compartir la cultura laboral de la calidad total; compartir con sus colegas su conocimiento tácito y trabajar en equipo (Silva, 2016b).

En el debate, el свс es coherente e idóneo para la producción y la escuela. Su visión es lineal: las competencias son integrales para actuar en un mundo complejo y poseen la dinámica para adecuarse al perenne cambio tecnológico del mercado de trabajo; las habilidades obtenidas durante la educación formal se aplican en diversos contextos y resuelven los problemas de la producción. Bellochio (2010, p. 11) sintetiza la convicción por las competencias como modelo pedagógico del siglo xxI y "[...] proyecto formativo mundial que aspira a cubrir todos los campos de la educación". Desde este enfoque se considera "natural" que la escuela se vuelva un anexo de la industria con la formación de mano de obra calificada; tampoco es discutible que la enseñanza siga siendo conductista por los verbos operativos que indican el logro de objetivos; o su interés por la ejecución, antes que en el desarrollo deliberativo de las personas.

Aun partidarios de las competencias, como Corvalán y Tardif (2013), aceptan su nexo con la pedagogía por objetivos del taylorismo industrial, pero matizan que no se limitan al ámbito laboral ni son mecanicistas. Por su parte, Coll (2007) reconoce el origen de las competencias y su pedagogía del espacio ocupacional, pero sostiene que se contextualizan y son la base para el aprendizaje a lo largo de la vida. Afirma que los enfoques neoconductistas en competencias no han superado la demanda del desempeño eficaz y lo observable, y existe un "entusiasmo un tanto acrítico con que se presentan [...] y las virtudes maravillosas que se les atribuyen" (p. 1). No obstante, se consideran ideales para educar en la globalización tecnológica y de la denominada sociedad del conocimiento.

\section{Economía y sociedad del conocimiento}

En 1973 Bell (citado en Treviño, 2015), afirmó que el conocimiento es el principal insumo con la llegada de la sociedad posindustrial. La noción de sociedad del conocimiento se popularizó en los noventa y se entendió como la organización social en que el conocimiento científico es el principal insumo para el desarrollo social, económico y cultural, y requiere sujetos adecuados para interactuar con él. Este conocimiento se asocia a la reflexión, la razón, el progreso, la ciencia y la tecnología, pero en el siglo xxI parece reducirse a su utilidad en la aplicación para la producción, y a la educación superior se le asignó la función de formar trabajadores del conocimiento. Otros conceptos para nombrar la fase actual del desarrollo socio-productivo del planeta son: economía del conocimiento, la era o sociedad de la información, sociedad del aprendizaje o economía de aprendizaje ${ }^{1}$.

En lenguaje contemporáneo, la economía del conocimiento es un área de oportunidad para el progreso material, y con las tecnologías de la información y comunicación (TIC) las escuelas mejorarán la enseñanza y el perfil de egreso. En ese autismo contextual no existe la ganancia del empresariado eliminando empleos y mermando las prestaciones del colectivo trabajador con la automatización y la robótica; tampoco, la menor preocupación por atender la conexión universal de las redes informáticas y postergar la cobertura mundial del servicio de agua potable o drenaje. En suma, en los últimos años el conocimiento se trocó en el principal insumo y valor agregado de la producción, pero en el planeta creció la inequidad social y económica. Una extensa cita del informe sobre desarrollo humano 2016, elaborado por el Programa de las Naciones Unidas para el Desarrollo (PNUD), muestra el panorama mundial de desigualdad, discriminación y exclusión material:

[...] las carencias humanas persisten. El progreso ha pasado por alto a grupos, comunidades $\mathrm{y}$ sociedades, y hay personas que se han quedado al margen. Algunas solo han logrado lo básico del desarrollo humano y otras ni siquiera eso. Además, han aparecido nuevos problemas para el desarrollo, que van de las desigualdades al cambio climático, pasando por las epidemias, la migración desesperada, los conflictos y el extremismo violento. (PNUD, 2016, p. 1).

...Una de cada nueve personas en el mundo padece hambre y una de cada tres, malnutrición [...] en todo el mundo mueren al día 18000 personas debido a la contaminación atmosférica [...] Las mujeres y las niñas, las minorías étnicas, los pueblos indígenas, las personas con discapacidad y los migrantes se ven privados de las dimensiones básicas del desarrollo humano [...] en todas las regiones las mujeres registran, en promedio, un Índice de Desarrollo Humano (IDH) más bajo que los hombres [...] solo entre el $10 \%$ y el $20 \%$ de los propietarios de tierras en los países en desarrollo son mujeres [...] Más de 370 millones de personas

1 No es el propósito del artículo elaborar una discusión sobre el significado o las implicaciones de los conceptos, porque las considero equivalentes por su nexo con la producción. Creo que se trata de una economía del conocimiento y no de una sociedad del conocimiento. No obstante, por ser de uso común y aceptado, uso indistintamente ambas nociones. 
de 70 países que declaran ser indígenas también sufren discriminación y exclusión en el marco jurídico, en el acceso a la educación en su propio idioma y en el acceso a la tierra, el agua, los bosques y los derechos de propiedad intelectual. Se calcula que más de 1000 millones de personas viven con alguna forma de discapacidad y están entre las más marginadas en la mayoría de sociedades [...] 244 millones de personas viven fuera de su país de origen. La mayoría son refugiados económicos que tienen la esperanza de mejorar sus medios de vida y enviar dinero a sus hogares, pero muchos migrantes, especialmente los 65 millones de desplazados forzosos del mundo, se enfrentan a condiciones extremas, como la falta de empleo, de ingresos y de acceso a servicios sanitarios y sociales más allá de la asistencia humanitaria de emergencia. A menudo, sufren acoso, animosidad y violencia en los países de acogida. (PNUD, 2016, p. 5).

Al respecto, la Unesco (2005) cuestiona la hegemonía del modelo técnico y científico como conocimiento legítimo y productivo, y la brecha cognitiva que separa a los países más favorecidos con los marginados. Agrega que todas las sociedades a su manera han tenido conocimiento y ayer como hoy el dominio de éste se acompaña de exclusiones y luchas sociales. Por eso habla en plural de sociedades del conocimiento que incluye lo social, lo ético y lo político, y objeta la privatización de los procesos de invención e innovación ${ }^{2}$. Se pronuncia por usar la biotecnología para mejorar la agricultura y combatir enfermedades como el sida, la tuberculosis y el paludismo. En sentido contrario, para la Organización para la Cooperación y el Desarrollo Económicos (OCDE) el conocimiento es parte del capitalismo industrial y a la educación parte de los servicios simbólicos. Su principal virtud es sustituir al capital físico en la generación, circulación y distribución de la riqueza, asimismo creó una nueva división internacional del trabajo (Villaseñor, 2003).

En la educación el desarrollo tecnológico orienta los contenidos y formas de transmisión del conocimiento. El aprendizaje se vuelve un proceso sin límites temporales para mantener actualizada la fuerza de trabajo. En México, se privilegia la difusión de una cultura informática en el estudiantado para la sociedad del conocimiento (objetivo 3.4 del PSE 2007-2102, SEP, 2007). Se encumbra la idea de que la escuela debe adaptarse al mercado laboral porque el

2 No obstante, la Unesco se refiere a la sociedad del conocimiento como única: "El nuevo paradigma es un ejercicio de cambio respecto de las prácticas educativas vigentes en las escuelas, de manera de hacerlas más pertinentes a las demandas de la sociedad del conocimiento" $(2014$, p. 36). conocimiento de hoy es efímero, pero no se especifica si es el tecnológico o de cualquier ciencia o disciplina. Como valor económico, la obsolescencia del conocimiento será más rápida que un procesador Pentium. Como ilustra Hirtt (2003), en la Era de la flexibilidad "el saber" es un producto perecedero determinado por la inestabilidad de puestos de trabajo que obligan a la gente a aprender otro oficio para poder emplearse. En coincidencia, para la Unesco: "La estabilidad del empleo viene 'atada' a las competencias requeridas por las nuevas tecnologías que se introducen aceleradamente" (s.f., p. 8). Así, en Estados Unidos un trabajador antes de los 40 años habrá desempeñado en promedio más de 10 empleos distintos, y el $80 \%$ de los nuevos puestos requiere habilidades de tratamiento de la información (Pérez, 2012, pp. 51 y 53).

Por ello, en México los planes del bachillerato se modificaron para impartir informática desde el tercer semestre y al estudiantado se le prepara para manipular el procesador de palabras, la hoja de cálculo y de diseño de presentaciones, más algunas nociones básicas de programación (Silva, 2016a). En la lógica del conocimiento obsoleto, estos contenidos son caducos con relación a las profesiones 2.0, que consisten en tuitear, desarrollar estrategias para redes sociales, medir los hashtags, entre otros. Los nuevos puestos se nombran marketing digital, optimizadores de sitios de búsqueda, expertos en analítica web y aplicaciones en teléfonos inteligentes (Herrera, 2013). Es la fuerza de trabajo con analistas simbólicos capaces de manipular símbolos, datos y palabras en una computadora. Y es una muestra del conocimiento mercantilizado y con valor agregado generado por el uso intensivo de las redes sociales. Otro cambio en la producción y el comercio es el modelo Cisco Systems. Para Castells (s.f.), este es el prototipo de la empresa; sus transacciones con proveedores y clientes funcionan a través de la red. Es una empresa virtual sin producción, pero que en realidad fabrica el $85 \%$ del equipo para el funcionamiento de internet.

Para cerrar la sección sobre la sociedad del conocimiento, más allá de la actualización tecnológica y su utilidad para la competitividad económica, no debe olvidarse que también se crearon dispositivos de vigilancia y satélites de localización para controlar. En los últimos años, Estados Unidos usa sensores de calor, cámaras y miras infrarrojas para capturar migrantes en su frontera con México. Igualmente, se saquean y monopolizan los recursos naturales de los pueblos indígenas para desarrollar la biotecnología, sin regresar las ganancias a las comunidades. En otras palabras, el conocimiento y la tecnología no siempre se usan como bienes sociales para construir un proyecto más humano. Por el momento, la economía del 
conocimiento obliga a la escuela a formar técnicos y profesionales con las competencias apropiadas al cambio tecnológico y transforma los procesos de enseñanza y aprendizaje con el fin de ligarse con el mercado laboral.

\section{Información y perfil de egreso}

Existe consenso en que la información y el conocimiento son los nuevos valores de uso y de cambio para la era digital. Se cree que el conocimiento avanza como maremágnum y lo que hoy era verdad, mañana no lo será. Entre tantos textos, documentos e informes sobre la economía del conocimiento, Pérez (2012) sintetiza así el escenario actual que indica la importancia de la información: a la fuerza física humana la sustituyó la fuerza animal, a esta la energía, y la superó la gestión digital de la información. Y las épocas se sucedieron de la de piedra (caza y pesca) a la agrícola (ganadería y comercio), y de la industrial (fábricas) a la información que se adquiere, procesa, analiza y comunica. Para ejemplificar el cambio de época, Riege (citado por Pérez, 2012, pp. 48-49) sostiene:

...en el automóvil, prototipo de la era industrial el $60 \%$ de su coste se debe a la materia prima y al trabajo físico que se dedica a su producción [...] en el ordenador prototipo de la era de la información [...] sólo el $2 \%$.

Siguiendo a Pérez (2012), este autor destaca que en dos años se produjo más información que en toda la historia de la humanidad y ésta se duplica cada dieciocho meses. Sus referentes son los millones de búsquedas en Google y la capacidad de almacenamiento de datos que de kilobytes pasó a gigabytes, hasta arribar a los Yottabytes. También en internet, que tardó cuatro años en llegar a la mayoría de la población, más rápido que la radio y la televisión. 0 la posibilidad de que en 2020 una computadora personal procese la información similar al cerebro humano. Ello gracias a la confluencia de la genética, la neurociencia y la nanotecnología. Después de la fascinación por la información, Pérez registra los bemoles: la celeridad de la difusión de datos genera en los individuos saturación, desconcierto y desinformación; la televisión divulga programas triviales, vacíos con la primacía de las formas sobre el contenido y las sensaciones sobre la reflexión.

Pese a las controversias respecto a la información y el desarrollo tecnológico útil para la producción y en menor medida para la gente, parece irreversible su aceptación en las escuelas. Ante la saturación de información, el perfil de egreso es de ciudadanos capaces de usar de modo eficaz y creativo los datos recibidos para convertirlos en conocimiento y aplicarlos en diferentes situaciones y contextos (Pérez, 2012). Verdad o mito, es la misma lógica de las competencias que por genéricas se vuelven omnipresentes en el sistema de manufactura esbelta. Si los empleos requieren de habilidades informáticas, desde la primaria saben manipular una computadora y en los siguientes niveles manejar el paquete de Office. Otro elemento en México es la enseñanza del inglés, porque es la nueva lengua franca de los negocios y el software.

En este contexto, para la economía del conocimiento o sociedad de la información el sistema educativo requiere incorporar las TiC al aula y al currículo escolar, así como en la formación del profesorado. Otra razón es porque han impactado la salud, las finanzas, el gobierno, la productividad industrial, y su omnipresencia es una oportunidad para "una educación más equitativa y de calidad para todos" (Unesco, 2014, p. 12).

En referencia a su beneficio, se observa el surgimiento de ciberciudadanos que a través de las redes sociales participan y logran un control social, ajeno al ciudadano convencional. Hasta se considera que las revueltas de 2006 en Chile y de 2011 en Medio Oriente y África del Norte se facilitaron por el uso de las Tic (Unesco, 2014, p. 16). Así, estas son la base de la alfabetización digital, que provee de competencias afines a la sociedad del conocimiento para no padecer la exclusión social y hace realidad los cuatro pilares de la educación: el aprender a conocer, porque difunde conocimientos como medio de información; el aprender a ser, pues facilita la expresión y el uso ético de la palabra; el aprender a hacer, porque aporta elementos para el desarrollo de la creatividad; y el aprender a vivir juntos, porque enlaza a las personas en espacios de participación e interacción social.

Cuando se propone la incorporación de las TIC, se otorga poco espacio para deliberar respecto de sus implicaciones en el aprendizaje y la manera de actuar de la juventud. Los motores de búsqueda facilitan parcialmente encontrar la información más pertinente para una tarea, porque aparece en primer lugar la más cercana a lo que se busca. A la vez, impide la reposada reflexión sobre cuál sitio elegir para realizar la tarea. Si agregamos la posibilidad de copiar y pegar, en la entrega de trabajos campea el plagio, el acomodo de párrafos de distintos artículos y la escasa opinión del estudiante ${ }^{3}$. Por otro lado, el

3 Experiencias en mi labor como docente en una universidad y un bachillerato. Es una situación generalizada, pero no se afirma que todo el estudiantado recurra a las prácticas mencionadas. 
uso constante de medios audiovisuales desalienta el gusto y el interés por la lectura en papel o en la red. A estos nativos digitales se les dispersa la atención preocupados por contestar desde sus celulares los mensajes de WhatsApp y Facebook, pero igual que los obreros polivalentes desarrollan la habilidad para responder a las preguntas en clase y platicar con sus amistades.

En la cotidianidad escolar se populariza el uso de las TIC para enseñar al estudiantado las competencias necesarias congruentes con la era digital, caracterizada por la incertidumbre y la complejidad. Algunas competencias que van más allá de la tecnología son: aprender a aprender, a conformar un pensamiento autónomo y crítico, y a lograr la autorregulación para convivir con grupos humanos heterogéneos. Se trata de forjar un capital humano capaz de diseñar proyectos personales, manejar sus habilidades socioemocionales y compartir, innovar, crear, tener espíritu emprendedor y autoevaluarse. Este es un perfil de egreso loable en el discurso, pero si las TIC no se adaptan a las personas y al proceso de enseñanza y aprendizaje, es factible que se fomente una didáctica tecnocrática que lleva al activismo irreflexivo y la hiperactividad mecanicista (Torres, 2012). Asimismo, entre las competencias del técnico, profesional o ciudadano actual, no son explícitos los rasgos que considera Torres (2012): personas cuya meta principal no sea ganar el mejor salario con el menor esfuerzo; o producir bienes que favorezcan la alienación o la explotación; o alcanzar una vida digna evitando la dominación.

En la controversia, se impone la idea de que la escuela y sus contenidos deben corresponder a la cotidiana exigencia del progreso tecnológico. A esto se enfoca hoy la educación a lo largo de la vida, que -es preciso insistir- es un eufemismo para reciclar constantemente la fuerza de trabajo, semejante a la actualización de Windows o del antivirus. Como expresa Pérez "Dale un pez, enséñale a aprender y podrá desenvolverse a lo largo de la vida" (2012, p. 53); así modificó el aforismo "no regales peces, sino enséñales a pescar", para compaginarlo con la noción de aprender a aprender, que en el pasado se nombró autodidactismo. Esta es la principal competencia en un mundo que ofrece la alfabetización digital o la exclusión del empleo. Pero la disyuntiva no depende de incorporar las TIC y el pensamiento de ser emprendedor en países como México, que ensamblan los productos de las multinacionales. La incorporación de la automatización y la robótica trajo consigo la reducción de ocupaciones, la merma salarial y de prestaciones, y el abatimiento de los puestos de planta.
Sennet (2000) analizó cómo creció el empleo temporal en Estados Unidos, la dinámica del mercado que obliga a la innovación permanente y la ampliación de la contratación en los servicios informáticos y procesamiento de datos. Descubrió que el colectivo obrero perdió el compromiso y la lealtad con la empresa. Sennet describe la transformación del trabajo derivado de la tecnología y la sustitución de las habilidades humanas, como las del panadero. Señala que en la panadería informatizada se pierde el contacto físico con los ingredientes y los panes; la persona supervisa todo el proceso en los iconos de la pantalla, asílos panaderos ya no saben hacer pan. Sobre el manejo de computadoras, afirma que no se usan muchos conocimientos en su tarea, porque se limita a presionar botones en un programa de Windows diseñado por otros. Ahora cualquier persona puede hacer pan, zapatos, trabajo de imprenta. Sennet comprendió que la tecnología informática trajo menos empleo y la escasa aplicación de las destrezas aprendidas.

Información reciente denota múltiples ejemplos del desplazamiento de las personas del trabajo por los robots. En las tiendas al menudeo la lucha por mejores salarios por hora se logra y sus utilidades disminuyen. Cadenas como Wal-Mart empiezan a sondear cuál es la tecnología que realice tareas repetitivas del colectivo trabajador, incluso actividades más complejas; con la ayuda de una computadora con el historial del cliente se le sugiere el juguete o la camisa de acuerdo con sus gustos. En algunas tiendas de Wal-Mart ya se experimenta con pantallas de tacto para que los clientes devuelvan la mercancía sin intermediación de los dependientes. Esto provocó la desaparición de casi 71000 trabajos en las tiendas (The New York Times, 2016). En el ramo de la elaboración de pizzas, Zume automatizó sus operaciones y pueden hacer 10 piezas más que en una pizzería con un personal normal. Un robot rocía la salsa de tomate, otro la extiende imitando los movimientos del chef y uno más coloca la pizza en el horno. A los humanos ahora les compete agregar el pepperoni y el queso. Aún enfrentan problemas de calibración de los robots cuando cambian la masa o la receta de la salsa (Los Angeles Times, 2017).

Una nueva ventaja del uso de robots para el empresariado, aparte de ahorrar el pago de salarios y prestaciones, es acortar los tiempos de entrega de productos y evitar grandes almacenamientos. Un ejemplo es la próxima fábrica de Adidas en Alemania, que contará con robots y automatización personalizada para producir 500000 pares de zapatos deportivos al año. El mismo camino recorrerán Nike y Apple, porque las máquinas pueden sustituir la cada vez más cara mano de obra humana. Y la automatización 
impulsará la seguridad en el trabajo, al transferir las labores más peligrosas a robots, de los cuales entre 2014 y 2018 se vendieron 400000 unidades. Aún faltará crear robots para faenas como coser delicadas piezas en prendas de vestir (The Wall Street Journal, 2016). En el ramo restaurantero, en San Francisco los comensales ordenan con un iPad, pagan con tarjeta de crédito y recogen su comida sin interactuar con meseros y sin mostrador (Miller, 2015). En el ámbito hotelero, en Japón un dinosaurio robot atiende en la recepción, saluda a los huéspedes y les asigna las habitaciones. Otros robots llevan el equipaje, cuelgan la ropa y limpian los cuartos, las personas ingresan al cuarto por reconocimiento facial y solicitan servicios con una tableta (Hiufu, 2015). Para cerrar, en la planta de Ford de Hagzhou, China, 650 robots sueldan y ensamblan estructuras de acero en los vehículos, y el proceso de pintura está mayormente automatizado. En China el interés es seguir siendo competitivos con la automatización, aunque se sabe que pagan bajos salarios (The New York Times, 2017).

Los ejemplos mencionados destacan el uso de la tecnología y los robots para desplazar mano de obra, interés del artículo. No obstante, el potencial de la tecnología para ayudar al ser humano es alentador. Un niño que recibió un doble trasplante de manos después de 18 meses ya come, escribe y se viste. Ello fue posible por el equipo de 40 personas, entre cirujanos, especialistas en trasplantes, psicólogos y trabajadores sociales que participaron. El infante comenzó a mover sus dedos utilizando los ligamentos originales de sus manos y su cerebro se está adaptando para controlar los movimientos y experimentar sensaciones (Agence France-Presse, 2017). Otros avances tecnológicos que parecen ficción rodean nuestra realidad: semáforos que regulan el tránsito, autos sin conductores, la inteligencia artificial. Una muestra es el sistema Watson, que fue entrenado en el campo de la oncología ingresando miles de datos de historias clínicas y sesiones médicas, pruebas de laboratorio, resultados de radiografías y resonancia magnética, más millones de páginas de textos y artículos científicos. A la información se añaden datos del paciente y el sistema sugiere un diagnóstico y propone el tratamiento más adecuado, con una confiabilidad de entre 90 y $95 \%$ (Flores, 2017).

En cuanto a la aplicación de la tecnología en las ciudades, a estas se les denomina inteligentes, Singapur es un prototipo: los jóvenes portan ropa con sensores que les indican la temperatura corporal, el pronóstico de lluvia o las rutas despejadas; en las aulas hay robots para enseñar a través de los juegos colaborativos; el sistema Code@SG instruye a estudiantes de entre seis y doce años para programar; se experimenta con vehículos autónomos compartidos para evitar el exceso de tráfico y de contaminación, y existen seis taxis sin conductor; la iniciativa Polaris desarrolla medicina genómica para diagnosticar enfermedades como la tuberculosis o el cáncer, o para identificar las cepas bacterianas más resistentes a los medicamentos (Ripa, 2016).

En el caso mexicano el perfil de egreso puede sintetizarse en un individuo con habilidades informáticas y con una actitud de trabajar en equipo. En la retórica de las ventajas tecnológicas y el uso de las TIC en la educación no es clara la utilidad del conocimiento si las máquinas realizan el trabajo. A menos que los técnicos o profesionales se dediquen a diseñar software, será poca la inventiva e imaginación que desarrollen. Más que los conocimientos adquiridos, importa la mentalidad competitiva para conseguir los puestos que aún dejan vacantes los robots.

\section{Conclusiones}

En el siglo XXI, igual que desde la década de los sesenta, a la educación, específicamente, a la universitaria se le asignó la función de impulsar el progreso y el bienestar material de los países. Entonces se difuminó la noción de capital humano asociado a los grados de escolarización, como base para obtener un empleo y éxito económico. A esta corriente se le denominó desarrollista, y no ha demostrado su viabilidad, al menos en los países del tercer mundo. En parte porque la calidad de vida en las naciones no depende exclusivamente de la educación formal. Ahora en la economía o sociedad del conocimiento, se supone que es posible ahondar la democratización del conocimiento y los saberes producidos, el derecho a la escolarización y la justicia social.

La responsabilidad de alcanzar los ideales descritos se le sigue encargando a la escuela. En tiempos de globalización educativa, económica y cultural se encontró que para responder a las demandas del empresariado de la era digital es pertinente adoptar un currículo en competencias. En el horizonte educativo el presente y el futuro es el mercado y es la guía para modificar el perfil de egreso. El sistema de producción toyotista o de manufactura esbelta es el referente con su trabajo en equipo, calidad total, cero errores y la polivalencia del operario. Pero el CBC no podrá resolver los problemas ni la brecha digital sin modificar también las condiciones socioeconómicas, pues como asevera Coll (2007): "Las aportaciones de los enfoques por competencias son muy valiosas, pero definitivamente tampoco son un remedio milagroso" (p. 4). 
En este complejo marco, se retoma el propósito del artículo: analizar que el avance tecnológico renovó el currículo y el perfil de egreso en el contexto de la sociedad del conocimiento. Con la incorporación de las TIC se pugna por una enseñanza en competencias. Términos como ambiente de aprendizaje, la enseñanza centrada en el alumnado, desterrar la memorización y la fragmentación del conocimiento, se volvieron lugar común. Pero en la cotidianidad, se mantienen los programas rígidos en su temporalidad, el examen y la evaluación estándar para estudiantes diferentes y el control docente en el salón de clases. Aún faltan esfuerzos para desaprender las prácticas heredadas de una escuela al servicio de la producción taylorista y que la denostada memorización no se sustituya por un chip de celular o el buscador de Google, proveedores de información instantánea, pero no de la capacidad para analizarla.

En el debate sobre el свс y la tecnología, desde sus promotores poco se cuestiona. No se delibera que el currículo es una construcción social e histórica que hoy se configura para proveer recursos a la economía con una enseñanza de contenidos pragmática, donde el saber se reduce a la información y las destrezas técnicas para procesarla (Elliot, 1999). Y que, como en México, el CBC como generador de un nuevo capital humano no ha revertido el escenario de que cada vez hay más pobres educados, como el $54 \%$ de la población con nivel de preparatoria y el $8 \%$ con posgrado (Muñoz, 2017). Será porque como país ensamblador de los productos de Estados Unidos, todavía el conocimiento no genera valor agregado como en las matrices.

El otro objetivo del texto fue resaltar cómo la tecnología, la automatización y la robótica cada vez despojan de los empleos a las personas y la mayoría no desarrolla las competencias adquiridas en el trabajo, de acuerdo con Sennet (2000). A su vez, desmejora las condiciones laborales, prestaciones y garantías de la fuerza de trabajo. Competir con los robots que no exigen aumento salarial ni se cansan, solo es factible aceptando rebajas en su remuneración. Pero la inestabilidad en el empleo y de diferentes modalidades la entendió Marx desde 1884 con el desarrollo de las máquinas, que profundiza la precariedad de la vida del colectivo obrero (Wisnieski, 2014). Por tanto, el discurso vigente de que el empleo se caracteriza por la incertidumbre no es nuevo. Solo hubo un periodo de estabilidad debido a las luchas del proletariado y el inicio del Estado benefactor o fordista, que entendió la conveniencia de garantizar la seguridad social a las personas: educación, salud, vivienda y estabilidad laboral. El periodo abarcó después de la depresión económica de 1929 hasta mediados de la década de los setenta.
Los tiempos de inestabilidad laboral continúan, como se citó en Unesco (s. f.). Rifkin (2008) ilustra la tendencia en el empleo por la fusión de las tecnologías informática y genética. Sostiene que la computadora es capaz de manipular los genes; así se pasará de la era industrial a la era del comercio genético. Esto obliga a repensar la naturaleza del trabajo. En los próximos años se profundizará la sustitución de secretarias, gerentes, obreros de fábrica, campesinos y cajeros de banco, entre otros. Una rama de la tecnología genética, según Rifkin (2008), es el pharming, que es capaz de clonar exactamente a un organismo vivo con las mismas normas y control que la línea de montaje de Henry Ford. Mediante el pharming aplicado en los animales, introduciendo un código genético, se podrán producir productos farmacéuticos y sustancias químicas en la leche, por ejemplo, de una cabra. En el agro, ya se clonó la vainilla en un laboratorio y se ahorraron mano de obra, y en la costura se automatizaron los procesos. Con tales avances, "el trabajador más barato en el mundo no será tan barato como la tecnología que lo reemplaza" (Rifkin, 2008, p. 24).

Por lo anterior, la permanencia en el empleo del colectivo obrero, técnico o profesional ya no depende de sus capacidades y habilidades laborales, porque los robots reemplazan sus tareas; en consecuencia, para obtener un puesto aceptan las condiciones ofrecidas por el patrón. En Ciudad Juárez, principal enclave de industria maquiladora en México, los contratos mensuales, la subcontratación y la merma en las prestaciones responden a la lógica de abatir sueldos para rentabilizar la inversión empresarial. La posibilidad de que las personas laboren menos horas para que haya más trabajo y mantener salarios dignos, como una manera de distribuir las ganancias generadas por la tecnología, no llegará si se mantiene el neoliberalismo económico. Por esto, el CBC para ligar a la escuela con el trabajo podrá cumplir su función, pero no logrará el mejoramiento de las condiciones laborales ni el disfrute de los servicios públicos de la gente.

Pero no se trata de estigmatizar a la tecnología, la robótica, la automatización, las máquinas y las computadoras. Es el momento de aprovecharlas para que los seres humanos abandonen las tareas rutinarias tanto mentales como operativas generadoras de enajenación. Que sea en inicio del ocaso del trabajo explotado, pues hasta el momento la flexibilización, desregulación y la subcontratación han instituido un trabajo precario. Se trata, como sostiene la Unesco (2005), de consolidar la cooperación científica internacional, complementar las investigaciones en favor de la sociedad mediante el equilibrio entre la difusión, validación, revisión de 
los datos y la protección de la propiedad intelectual. Es tiempo de frenar los monopolios del mundo militar y empresarial que imponen sus agendas de investigación a las universidades, sin metas utilitaristas y acotar las ganancias de las farmacéuticas en beneficio de la gente marginada en todo el planeta. Es adherirse a la consigna de que el conocimiento es un patrimonio mundial, no un bien privado.

Finalmente, el diseño y la definición curricular contienen ideas de sociedad, de ser humano y valores. Por el momento, el currículo como preparación para el trabajo es hegemónico, implica una ideología y es tecnocrático (Silva, 2016b). Y los elementos comunes en la noción de competencia son las habilidades, conocimientos, destrezas, actitudes y valores para aplicarse en un trabajo y lograr competitividad industrial. Su universo para proponer el CBC son los cambios en la tecnología y la organización del trabajo, no las condiciones socioeconómicas y políticas de un país con grandes desigualdades de bienestar. Una opción es un currículo humanista, solidario, que aspira a lo colectivo, diferenciado, opuesto a que la información y el conocimiento sean los cimientos del capitalismo cognitivo del siglo XXI.

\section{Referencias}

Agence France-Presse. (20 de julio de 2017). Niño con trasplante de manos, capaz de comer, escribir y vestirse. La Jornada. Recuperado de http://www.jornada.unam. $\mathrm{mx} / 2017 / 07 / 20 /$ ciencias/a02n1cie

Báez, M. (2006). Elementos para la discusión de la competencia laboral en México. En C. Barrón (Coord.), Proyectos educativos innovadores. Construcción y debate (pp. 16-51). México, D. F.: CESU-UnAM.

Barrón, C. (2013). Formación profesional en la educación superior. Proyectos y prácticas curriculares. México, D. F: Díaz Santos.

Bellochio, M. (2010). Educación basada en competencias y constructivismo. Un enfoque y un modelo para la formación pedagógica del siglo XXI (2.a ed.). México, D. F.: ANUIES-Universidad de Colima-UACJ.

Castel, R., Kessler, G., Merklen, D. y Murard, N. (2013). Individuación, precariedad, inseguridad ¿desinstitucionalización del presente? Buenos Aires: Paidós.

Castells (s. f.) Lección inaugural del programa de doctorado en la Universitat Oberta de Catalunya sobre la sociedad de la información y el conocimiento. Recuperado de http://www.uoc.edu /web/cat/ articles/castells/ castellsmain6.html
Coll, C. (2007). Las competencias en la educación escolar: algo más que una moda y mucho menos que un remedio. Aula de Innovación Educativa, 161.

Comboni, S. y Juárez, J. (2001). Resignificando el espacio escolar. La innovación y la calidad educativa en una nueva práctica pedagógica. México, D. F.: Universidad Pedagógica Nacional.

Consejo Nacional de Normalización y Certificación de Competencias (s. f.). Diplomado "La diversidad y la Educación Media Superior”. Presentación en pdf.

Coriat, B. (2005). El taller y el robot, ensayos sobre el fordismo y la producción en masa. México, D. F.: Siglo XXI.

Corvalán, 0. y Tardif, J. (2013). Fundamentos teóricoprácticos de la educación por competencias. En 0. Corvalán, J. Tardif y P. Montero (Coords.), Metodologías para la innovación curricular universitaria en el desarrollo de competencias (pp. 17-55). México, D. F.: ANUIEs, Colección Documentos, Serie Bitácora.

De Ketele, J. (2008). Enfoque sociohistórico de las competencias en la enseñanza. Recuperado de http://www. ugr.es/local/recfpro/rev123ART1.pdf

Elliot, J. (1999). El papel del profesorado en el desarrollo curricular: una cuestión irresuelta en los intentos ingleses de reforma curricular. En Volver a pensar la educación. Prácticas y discursos educativos. (Congreso Internacional de Didáctica) (2. e ed.) (pp. 245-272). Madrid: Morata.

Flores, J. (21 de marzo de 2017). Inteligencia artificial y salud. La Jornada. Recuperado de http://www.jornada. unam.mx/2017/03/21/opinion/a03a1cie

Gimeno, J. (2002). El currículum: una reflexión sobre la práctica (8. ${ }^{\mathrm{a}}$ ed.). Madrid: Morata.

Herrera, C. (3 de junio de 2013). Profesiones 2.0 Extraños puestos en los organigramas. La Jornada. Recuperado de http://www.jornada.unam.mx/2013/06/03/ política/002n1pol

Hirtt, N. (2003). Los nuevos amos de la escuela. El negocio de la enseñanza. Madrid: Minor Network, Editorial digital.

Hiufu, M. (8 de septiembre de 2015). Un hotel dirigido por robots abre sus puertas en Japón. Reuters. Recuperado de http://www.cnnexpansion.com/ tecnologia/2015/07/17/hotel-de-robots-abre-suspuertas-automaticas-en-japon

Los Angeles Times. (6 de julio de 2017).Zume, la pizzería con robots cocineros. ElDiario Digital. Recuperado de http:// diario.mx/Estados_Unidos/2017-07-06_c0b32f90/ zume-la-pizzeria-con-robots-cocineros/ 
Lundgren, U. (1997). Teoría del currículum y escolarización (2 ${ }^{\mathrm{a}}$ ed.). Madrid: Morata.

Midgley, J. (2001). Growth, redistribution, and welfare: toward social investment. En Giddens, A. (Ed.). The global third way debate (pp. 157-171). Cambridge: Polity Press.

Miller, C. (8 de septiembre de 2015). Abren restaurante sin meseros ni cajeros en San Francisco. New York News Service. Recuperado de http://diario.mx/Nyt/201509-08_2d95aeeb/abren-restaurante-sin-meseros-nicajeros-en-san-francisco/

Muñoz, C. (1993). Bases para la modernización curricular en A. de Alba (Coord.). El currículum universitario de cara al nuevo milenio (pp. 80-92). México, D. F.: Secretaría de Desarrollo Social-Universidad de Guadalajara-UNAM.

Muñoz, P. (21 de junio de 2017). Crece número de mexicanos con educación que viven en pobreza. $L a$ Jornada. Recuperado de http://www.jornada.unam. $\mathrm{mx} / 2017 / 06 / 21 /$ sociedad/034n1soc

Organización de las Naciones Unidas para la Educación, la Ciencia y la Cultura-Unesco. (2005). Hacia las sociedades del conocimiento. París: Unesco.

Organización de las Naciones Unidas para la Educación, la Ciencia y la Cultura-Unesco. (2014). Enfoques estratégicos sobre las TIC en educación en América Latina y el Caribe. Chile: Oficina Regional de Educación para América Latina y el Caribe.

Organización de las Naciones Unidas para la Educación, la Ciencia y la Cultura-Unesco. (s. f.). Desafíos de la educación. Diez módulos destinados a los responsables de los procesos de transformación educativa. Buenos Aires: Instituto Internacional de Planeamiento de la Educación-Ministerio de Educación de la Nación.

Pérez, Á. (2012). Educarse en la era digital. México, D. F.: Morata-Colofón.

Programa de las Naciones Unidas para el Desarrollo-PNUD. (2016). Panorama general. Informe sobre Desarrollo Humano 2016 Desarrollo Humano para Todos. Canadá: Lowe-Martin.

Rifkin, J. (2008). Tiempo libre para disfrutarlo o hacer filas de desempleados. En L. J. Álvarez (coord.) Un mundo sin trabajo (3. ed.) (pp. 15-49). México, D. F.: Dríada.

Ripa, J. (11 de octubre de 2016). El país del futuro ya existe. Y se llama Singapur. El País. Recuperado de https://elpais.com/elpais/2016/10/11/talento_digital/1476203282_140331.html
Rojas, I. (2000). La educación basada en normas de competencia (EBNC) como un nuevo modelo de formación profesional en México. En M. Á. Valles (Coord.) Formación en competencias y certificación profesional (pp. 45-75). México, D. F.: UNAM-CESU.

Salinas, D. (2000). La planificación de la enseñanza: ¿Técnica, sentido común o saber profesional? En J. Angulo y N. Blanco (Coord.). Teoría y desarrollo del currículum (2. ${ }^{\mathrm{a} e d}$.), (pp. 15-160). Málaga: Aljibe.

Secretaría de Educación Pública. (2006). Programa Nacional de Educación 2001-2006.

Secretaría de Educación Pública. (2007). Programa Sectorial de Educación 2007-2012.

Secretaria de Educación Pública. (2010). Las competencias genéricas en el estudiante del bachillerato general.

Secretaría de Educación Pública-Subsecretaría de Educación Media Superior. (2008). Documento de Trabajo Reforma Integral de la Educación Media Superior en México: La creación de un Sistema Nacional de Bachillerato en un marco de diversidad.

Selecciones del Reader's Digest. (1985). Gran diccionario enciclopédico ilustrado (26. a ed.). México, D. F.: Reader's Digest México.

Sennet, R. (2000). La corrosión del carácter. Las consecuencias personales del trabajo en el nuevo capitalismo (3. ed.). Barcelona: Anagrama.

Silva, C. (2016a). El currículo basado en competencias en el bachillerato mexicano. El enfoque unidimensional al mercado. Juárez: UACJ.

Silva, C. (2016b). La enseñanza en competencias en la Educación Media Superior. El mercado como presente y futuro. En J. Chávez, y I. R. Álvarez, Investigación interdisciplinaria. Una mirada desde el norte de México (pp. 209-250). Juárez: UACJ.

The New York Times. (14 de mayo de 2017). China, el país de la mano de obra barata, se robotiza. El Diario Digital. Recuperado de http://diario.mx/Economia/2017-0514_54ead432/china-el-pais-de-la-mano-de-obrabarata-se-robotiza/

The Wall Street Journal. (10 de junio de 2016). Grandes empresas confían manufactura a robots. Recuperado de http://diario.mx/Economia/2016-06-10_15ea896e/ grandes-empresas-confian-manufactura-a-robots /

The WallStreetJournal.(19 dejulio de 2017).Toman robotslugar de trabajadores en tiendas. El Diario Digital. Recuperado dehttp://diario.mx/Economia/2017-07-19_afd45978/ toman-robots-lugar-de-trabajadores-en-tiendas/ 
Torres, J. (2012). La justicia curricular. El caballo de Troya de la cultura escolar (2. ${ }^{\mathrm{a}}$ ed.). Madrid: Morata.

Treviño, E. (2015). La educación superior y el advenimiento de la sociedad del conocimiento. Equivalencias y diferencias en los discursos y políticas de transformación educativa en los ámbitos nacional e internacional. México, D. F.: ANUIES.

Uroz, J. (2010). La llamada crisis del modelo del Estado de bienestar. Reestructuración y alternativas. Revista Miscelánea Comillas, 68(132) 299-311.
Villaseñor, G. (2003). La función social de la educación superior en México. La que es y la que queremos que sea. México, D. F.: UAM-CESU-UNAM-UV.

Wisniewski, M. (17 de octubre de 2014). Precariado: ¿una clase nueva o nueva lucha de clases? $L a$ Jornada. Recuperado de http://www.jornada.unam. $\mathrm{mx} / 2014 / 10 / 17 /$ opinion/026a1pol 